\title{
Análise de dados e imagens fotográficas da condição atual de uma área da zona ripária do Rio Tranqueira, no município de Guaraí/TO
}

As matas ciliares estão situadas às margens de córregos, riachos, lagos, rios e nascentes, e são fundamentais para o processo de preservação e conservação deste recursos hídricos. O Rio Tranqueira nasce próximo à BR-153 e desemboca no Rio Tocantins, e é importante para o ecossistema local e para a comunidade. No entanto, a degradação através do desmatamento desenfreado tem colocado em risco este recurso hídrico tão valioso. Nesse sentido, o objetivo deste trabalho fo avaliar através da coleta de dados e de imagens fotográficas a atua situação da zona ripária em uma extensão total de 1,6km de mata ciliar. Fez-se comparação da largura da vegetação encontrada com o que determina a Legislação brasileira. Para a realização da coleta de dados foram utilizados métodos quantitativos e qualitativos, bem como a técnica de metragem proposta por Silva (2003), adaptada para a realização deste trabalho. Os resultados foram computados e se procedeu a aplicação de estatística descritiva. Com os dados obtidos, realizou-se palestra educativa em uma escola pública local. Para avaliar o nível de conhecimento dos alunos acerca do que foi proposto realizou-se a aplicação de um questionário, utilizando-se o método dedutivo proposto por Gil (2008). A situação atual do Rio Tranqueira é uma mata ciliar bastante degradada, poluição e assoreamento. Conclui-se que falta fiscalização por parte de órgãos responsáveis para fazer valer a Lei 12651/2012, bem como falta conscientização da população em relação à importância da preservação deste recurso hídrico, principalmente através da adoção pelas escolhas de metodologias para ensinar os seus alunos à importância dos leitos d'água para a continuidade da vida no planeta.

Palavras-chave: Mata ciliar; Lei Federal 12651; Desmatamento; Sensibilização.

\section{Data analysis and photographic images of the current condition of an area of riparian zone of River Tranqueira, in the municipality of Guaraí/TO}

The riparian forests are located on the banks of streams, streams, lakes, rivers and springs, and are fundamental for the process of preservation and conservation of these water resources. The River Tranqueira is born near the BR-153 and flows into the Tocantins River, and is important for the local ecosystem and the community. However, degradation through unbridled deforestation has jeopardized this valuable water resource. In this sense, the objective of this work was to evaluate the situation of the riparian zone in a total extension of $1.6 \mathrm{~km}$ of riparian forest through data collection and photographic images. We compared the width of the vegetation found with what determines the Brazilian legislation. For the collection of data, quantitative and qualitative methods were used, as wel as the technique proposed by Silva (2003), adapted for the accomplishment of this work. The results were computed, and the descriptive statistics were applied. With the data obtained, an educational lecture was held at a local public school. To evaluate the students' level of knowledge about what was proposed, a questionnaire was applied using the deductive method proposed by Gil (2008). The current situation of the River Tranqueira is a very degraded riparian forest pollution and silting. It is concluded that there is a lack of supervision by bodies responsible for enforcing Law 12651/2012, as well as lack of awareness of the population regarding the importance of preserving this water resource, mainly through the adoption of methodologies to teach their students to importance of water beds for the continuity of life on the planet.

Keywords: Ciliary forest; Federal Law 12651; Deforestation; Awareness.

Topic: Engenharia de Recursos Hídricos

Reviewed anonymously in the process of blind peer.
Received: 16/12/2017

Approved: $28 / 12 / 2017$
Laura Pereira de Oliveira Silveira

Instituto Federal de Rondônia, Brasil

http://lattes.cnpq.br/3473714491524893

laurasilveirazootec@gmail.com

Evania Alves de Sousa

Faculdade Guaraí, Brasil

http://lattes.cnpq.br/1141857455938869

evaniaalvesdesousa@outlook.com

Ana Paula Martins Guimarães

Universidade Federal do Tocantins, Brasil

http://lattes.cnpq.br/5309168123830683

biologa.apmg@gmail.com
Niclair Costa Dourado

Faculdade Guaraí, Brasi

http://lattes.cnpq.br/5700941457639680

niclaircd@gmail.com
Referencing this:

SILVEIRA, L. P. O.; SOUSA, E. A.; GUIMARÃES, A. P. M.; DOURADO, N. C.. Análise de dados e imagens fotográficas da condição atual de uma área da zona ripária do Rio Tranqueira, no município de Guaraí/To. Natural Resources, v.7, n.2, p.32-42, 2017. DOI: http://doi.org/10.6008/SPC2237-9290.2017.002.0004 


\section{INTRODUÇÃO}

A água é a base fundamental sobre a qual se desenvolvem os processos bioquímicos e fisiológicos que permitem a continuidade da vida na terra. Segundo dados da UNESCO, as águas doces representam apenas $2,7 \%$ da disponibilidade hídrica total do planeta. Destas, $72 \%$ encontram-se mobilizadas em geleiras, icebergs e calotas polares, e o restante está distribuído da seguinte maneira: 22,4\% armazenadas em aquíferos e lençóis subterrâneos; 0,36\% em rios, lagos e pântanos; e 0,04\% na atmosfera. Estes dados demonstram que a quantidade de água doce disponível para consumo representa menos de $1 \%$ da disponibilidade hídrica mundial (VARGAS, 1999). De acordo com Roberto et al. (2017), esse recurso natural está sendo disponibilizado em menor quantidade no planeta a cada ano devido às fortes ações antrópicas.

Dentre os fatores que interferem diretamente sobre o volume e a qualidade da água disponível no Brasil está a destruição da vegetação existente nas margens e entornos das nascentes e dos cursos d'água. Entende-se por vegetação ciliar ou ripária aquelas encontradas às margens de rios, riachos, lagos e nascentes (MARTINS, 2007). Estas desempenham importante papel ambiental e ecológico, principalmente no que diz respeito à manutenção do volume e qualidade da água; estabilidade e controle da erosão do solo; redução dos efeitos de enchentes; filtragem de resíduos de produtos químicos; regularização do regime hídrico; corredores ecológicos (KRUPEK et al., 2006) que servem de habitat para diferentes espécies animais e contribuem para a manutenção da biodiversidade da fauna local; dispersão vegetal e manutenção do regime aquático.

Estas matas pertencem a áreas de saturação hídrica formadas por vegetação que seguem as margens das micro e macrobacias, desde a sua nascente ao seu desemboco. Sua dinâmica e promoção da biodiversidade colaboram com a preservação da fauna e flora (BISHOP et al., 2008). Segundo Castro et al., (2012), o desmatamento das zonas ripárias têm sido uma das principais causas de morte dos rios, lagos e nascentes, prejudicando a biodiversidade terrestre e aquática e causando grande prejuízo ecológico, econômico e social. A remoção das matas ciliares desencadeia processos de erosão no solo gerando prejuízo à hidrologia regional, redução da biodiversidade e degradação de extensas áreas (ALVARENGA et al., 2006)

De acordo com Milaré et al. (2012), em setembro de 1965 um Código Florestal foi instituído por meio da Lei 4771/1965. Esse código passou por sucessivas transformações ao longo dos anos, sempre objetivando aprimorar as leis de proteção ao meio ambiente e redução dos impactos ambientais. No entanto, Milaré et al. (2012) ressaltam que a morosidade na aplicação dessas normas resultou na criação de uma nova legislação, a Lei 12651/2012. Essa lei, segundo Silva (2012), constitui as áreas declivosas e com coberturas topográficas da zona ripárias como áreas vulneráveis, enquadrando-se como Áreas de Preservação Permanente (APP), sendo de fácil limitação. As faixas simétricas das APPs podem ser fiscalizadas e são protegidos do desmatamento.

A microbacia hidrográfica do Rio Tranqueira está localizada junto ao município de Guaraí/TO. A nascente do Rio Tranqueira está localizada no território do Município de Guaraí e desemboca no rio Tocantins. Com extensão de aproximadamente $16 \mathrm{~m}$ de comprimento, este rio, segundo a Agência de Defesa 
Agropecuária do Estado do Tocantins (ADAPEC), abastece a agricultura nos dias de estiagem através de sistemas de irrigação e oferece suporte para a pecuária local.

Além disso, o rio também exerce papel importante nas indústrias locais, como a fábrica de alvenaria para produção de tijolos a partir de argilas retiradas de seu solo, fábrica de milho verde, irrigação de hortaliças entre outras atividades que abastecem a economia do município, assim como a utilização de certos trechos do Rio utilizados para diversão. Sendo a zona ripária um fator determinante para a sobrevivência das macros e microbacias essencial para a preservação da biodiversidade, este trabalho tem por objetivo avaliar por meio de registros fotográficos a atual situação da zona ripária do Rio Tranqueira, comparando os resultados obtidos com o que estabelece a legislação vigente.

\section{MATERIAIS E MÉTODOS}

Foram realizados registros fotográficos e coleta de dados, no que diz respeito ao tamanho da mata ciliar do Rio Tranqueira, localizado no Município de Guaraí/TO, bem como uma palestra educativa com a aplicação de um questionário para os alunos de uma escola do município, a fim de apurar a percepção da população em relação a importância da preservação do Rio Tranqueira para a comunidade local. O Município de Guaraí, predisposto na figura 1, está localizado na Região Norte do Brasil, mesorregião de Miracema do Tocantins, parte ocidental do estado, com as coordenadas $08^{\circ} 50^{\prime} 03^{\prime \prime}$ S e $48^{\circ} 30^{\prime} 37^{\prime \prime} \mathrm{O}$, possuindo uma área de $22.772 \mathrm{~km}^{2}$ (IBGE, 2016). Tocantins é o estado mais jovem da Federação, com apenas 27 anos de emancipação.

O estado do Tocantins tem grande destaque na produção agropecuária do país e é considerando pelo Ministério da Agricultura como a última fronteira agrícola do mundo, fazendo parte do acrônimo MATOPIBA, que compreende ainda parte do Estado do Maranhão, Piauí e Bahia. Possui um clima tropical sazonal com período chuvoso e seco. O período chuvoso compreende os meses de novembro a abril e o período seco vai de maio a outubro (TOCANTINS, 2012). No município de Guaraí há grande predominância da agricultura familiar de subsistência e pequenas criações agropecuárias, principalmente nos arredores do Rio Tranqueira, onde é encontrada também a presença de moradores ribeirinhos.

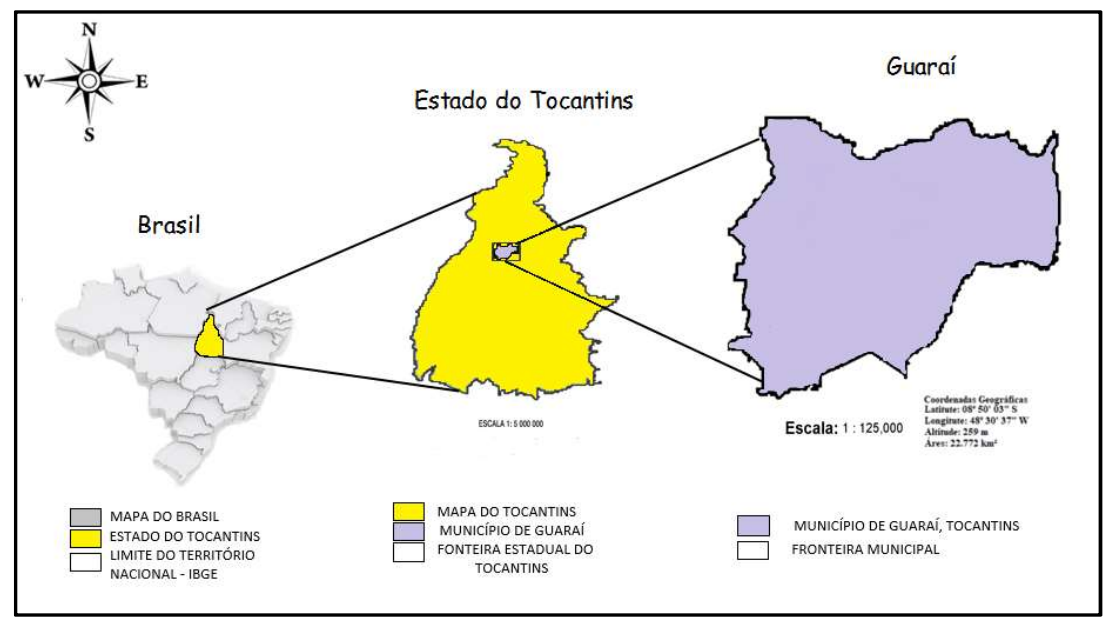

Figura 1: Mapa mostrando o estado do Tocantins e o município de Guaraí, onde se localiza o Rio Tranqueira. 
O experimento foi realizado na zona ripária do Rio Tranqueira no período compreendido entre janeiro e julho de 2017. Tendo por objetivo fazer uma estimativa da atual situação florestal do Rio, duas áreas foram escolhidas para a realização da coleta de dados. A figura 2 mostra, através de imagens de satélite fornecidas pelo Google Earth, o local das áreas de coleta dos dados, representadas como área "A", área de acesso público (margem esquerda) e privado (margem direita), com a longitude de $48^{\circ} 5797^{\prime \prime} \mathrm{S}$ e latitude média de $-8^{\circ} 86^{\prime} 72^{\prime \prime} \mathrm{O}$ e, área " $\mathrm{B}$ ", área de acesso privado, com longitude de $48^{\circ} 50^{\prime} 81^{\prime \prime} \mathrm{S}$ e latitude média $8^{\circ} 86^{\prime} 26^{\prime \prime}$ O. Em cada uma das duas áreas selecionadas para a avaliação, foram determinados pontos onde as medições foram realizadas, totalizando cinco pontos.

O levantamento dos dados na zona ripária do Rio Tranqueira aconteceu no período matutino, e teve duração de aproximadamente 5h. Para tanto, foram utilizados aparelho de GPS, câmera fotográfica, trena, caneta, papéis e equipamentos de proteção individual (EPI). Utilizou-se o método qualitativo (no que diz respeito ao registro de imagens fotográficas) e o quantitativo (na representação dos dados coletados). Segundo Malhotra (2006), o método quantitativo contabiliza os dados analisados e facilita a explicação estatística das análises, enquanto o método qualitativo esclarece as problemáticas que surgiram durante a pesquisa.

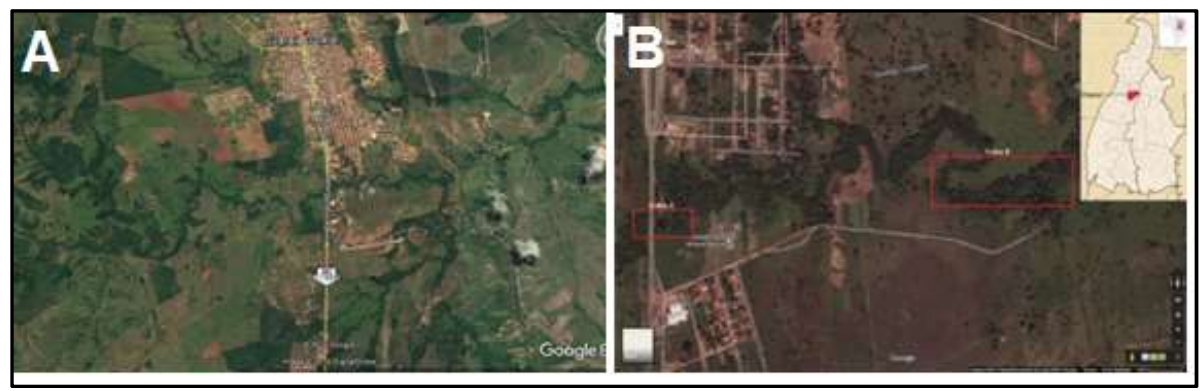

Figura 2. A) Localização da área de acesso público; e B) localização da área de acesso privado.

A zona ripária do rio foi medida pela técnica de metragem sistematizada, proposta por Silva (2003), e adaptada para a realização deste trabalho. Segundo Silva (2003), essa técnica tem como base a combinação entre faixas de vegetação, obtendo, com o resultado, as faixas mínimas e máximas necessárias. O primeiro levantamento de dados ocorreu na área de acesso privado, localizada a aproximadamente $6 \mathrm{~km}$ da cidade de Guaraí. Houve auxílio de um guia para a realização do percurso.

Com a utilização de um aparelho GPS foram medidos $800 \mathrm{~m}$ de comprimento em torno da área de preservação permanente do rio. Nesse perímetro, foram colocados piquetes de madeiras para demarcação dos lugares de avaliação da mata ciliar. Estes piquetes foram colocados a $200 \mathrm{~m}$ de distância entre cada um, e com a ajuda de uma trena, mediu-se a quantidade de mata ciliar existente desde a calha do rio até a extremidade da zona ripária. O procedimento foi igualmente realizado nas duas margens e nas duas áreas de acesso (público e privado). Na área de acesso público, o local onde o levantamento de dados foi realizado está situado próximo a BR-153. O proprietário da área de acesso solicitou que esta informação não fosse divulgada. 
Com auxílio de câmera fotográfica, realizou-se registro da atual condição do Rio Tranqueira, capturando imagens de poluição, assoreamento e desmatamento, quando havia, nas duas áreas de observação (pública e privada). Os dados obtidos foram tabelados e analisados a partir de estatística descritiva.

Posterior à obtenção dos resultados, realizou-se uma palestra educativa em uma escola local escolhida aleatoriamente. A palestra teve duração de $40 \mathrm{~min}$, e houve participação de 66 alunos. Para a realização desta, utilizou-se equipamento multimídia, notebook, papel e caneta. Foram apresentados os registros fotográficos realizados no perímetro do Rio Tranqueira, bem como imagens cedidas pela Secretaria Municipal do Meio Ambiente com registros deste rio há 20 anos. Durante a palestra, foram apresentados dados que indicam a importância da mata ciliar para a preservação dos ecossistemas, ressaltando o papel que o Rio exerce para a comunidade de Guaraí e a importância da sua conservação.

Ao final da palestra foi aplicado um questionário com a finalidade de aferir a compreensão dos alunos a respeito da importância do rio. Para tanto, a metodologia utilizada foi o método dedutivo proposto por Gil (2008). Segundo o autor, este método tem seus princípios fundamentados na veracidade dos fatos e, através dele, é possível chegar a uma conclusão puramente formal, usando-se de lógica.

\section{RESULTADOS}

As figuras 3 e 4 expressam a quantidade de mata ciliar remanescente às margens do Rio Tranqueira ao longo do transecto selecionado para a coleta da quantificação da área da biomassa vegetal existente ao longo do gradiente, observadas durante o período de coleta dos dados nas duas margens do Rio no acesso privado, sendo que a Figura 3 diz respeito à área de acesso privado do Rio, e a figura 4 mostra os resultados obtidos na área de acesso público (margem esquerda) e privado do Rio (margem direita). Na área de acesso privado os valores encontrados na margem esquerda foram de 9, 30, 14, 25 e 16m de vegetação observados respectivamente nos cinco pontos avaliados; na margem direita os valores obtidos foram de $30,40,35,30$ e 40 metros de mata, respectivamente.

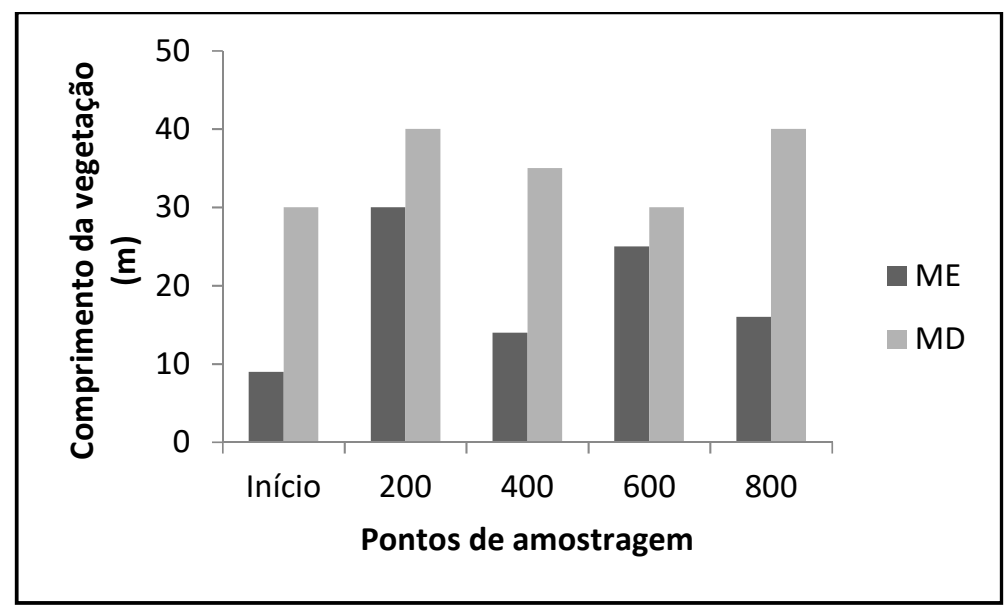

Figura 3: Comprimento de mata ciliar na área de acesso privado (margens esquerda e direita). 
De acordo com os resultados expressos na figura 3, com dados coletados nas duas margens do Rio Tranqueira na área de acesso privado, é possível observar que a margem direita do Rio apresenta uma área vegetal significantemente maior em relação à margem esquerda ao longo do gradiente. Esta discrepância com relação a estes resultados pode ter íntima relação ao tipo de utilização dos recursos naturais na margem direita do Rio, possibilidades de visitação antrópica e ao desmatamento para a realização de pequenas culturas.

A figura 4 apresenta os resultados da área de biomassa vegetal das duas margens do Rio no perímetro público. É possível notar que no perímetro público do Rio a área de cobertura vegetal também apresenta marcante diferença entre as duas margens, sendo que, neste perímetro a margem esquerda foi quem apresentou maior cobertura de mata ciliar. $\mathrm{Na}$ área de acesso público, os resultados encontrados à margem esquerda foram de 30, 32, 34, 30 e 25m de vegetação, respectivamente, e na margem direita; apenas 4, 9, 15,10 e $20 \mathrm{~m}$ de vegetação foram observados nos cinco pontos avaliados.

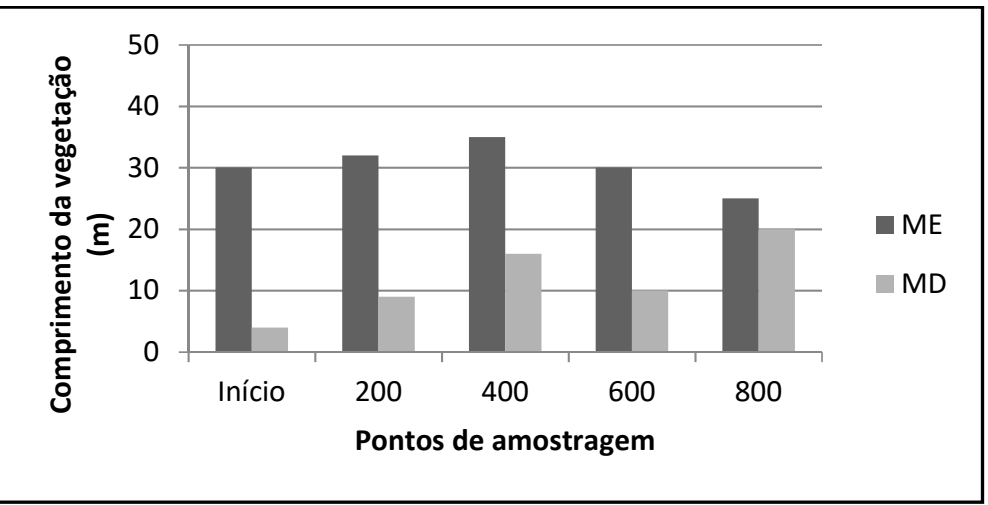

Figura 4: Comprimento de mata ciliar na área de acesso público (margem esquerda) e privado (margem direita).

Ao analisar as imagens fotográficas, é possível observar que a zona ripária do Rio Tranqueira apresenta forte antropização e uma vegetação bastante fragmentada. $O$ solo possui pouca vegetação rasteira e as margens do Rio estão assoreadas em ambas as áreas de estudo. O lado esquerdo do Rio na área de acesso privado foi o que apresentou maior estágio de degradação, como pode ser observado nas Figuras 5 e 6 do presente trabalho.

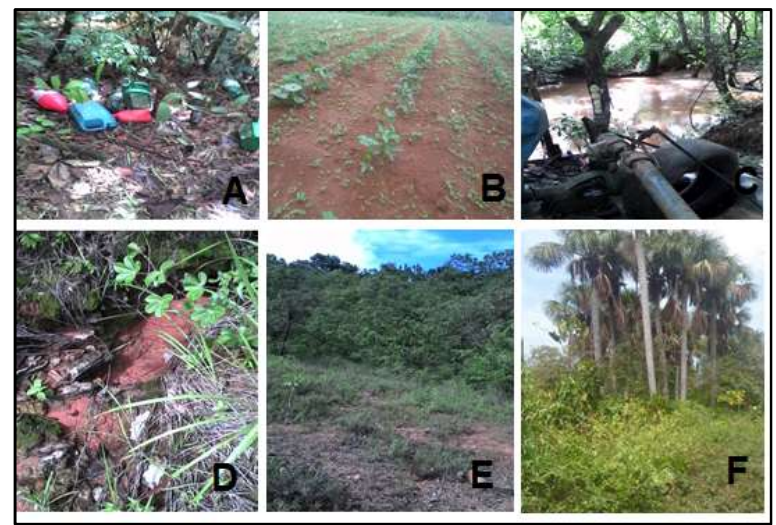

Figura 5: A) Vasilhames de defensivos agrícolas abandonados em local próximo ao Rio; B) Área desmatada para a prática da agricultura; C) Captador de água em péssimo estado de conservação e com vazamento de óleo dentro do Rio; D) Olho d'água; E) Área desmatada com pouca vegetação rasteira e solo descoberto; e F) Vereda existente próximo a área analisada. 


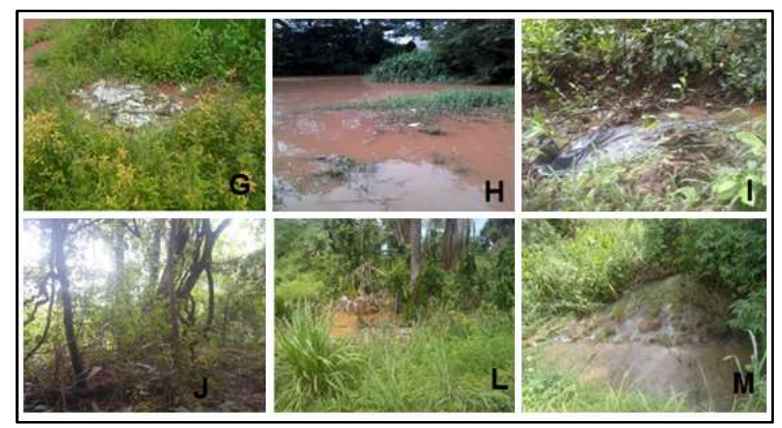

Figura 6: G), H), e I) lixo encontrado às margens e dentro do Rio; J) Vegetação arbórea fragmentada, com pouca vegetação rasteira; L) e M) pequena vereda com poluição visível.

\section{DISCUSSÃO}

A mata ciliar é considerada um elemento importante na redução dos impactos causados pela poluição graças ao seu mecanismo de filtragem, evitando também o assoreamento das macro e microbacias (MARTINS, 2007). Desempenha papel fundamental na paisagem ecológica, servindo como corredor ecológico, possibilitando a entrada e saída de animais e, consequentemente, favorecendo a dispersão de pólen e sementes, interligando importantes fragmentos florestais dentro de sua extensão (SILVA, 2013) e acomodando espécies de fauna e de flora que podem ser endêmicas daquela área específica.

Grande parte da área que deveria ser destinada a preservação do Rio foi retirada para a prática da agricultura, conforme mostrado na figura 5B, resultando em menos da metade de APP exigida por lei. Nesta margem foram encontrados, por exemplo, vários vasilhames de defensivos agrícolas vazios, como ilustrado na figura $5 \mathrm{~A}$, deixados a cerca de $2 \mathrm{~m}$ da margem, demonstrando a falta de fiscalização junto aos órgãos públicos, uma vez que pelas normas vigentes para a utilização de defensivos, o usuário é responsável pela devolução e transporte de embalagens vazias até a unidade de recebimento indicada na nota fiscal do produto no ato da compra, no prazo máximo de até um ano após a data de aquisição. Os postos de recebimento, por sua vez, são obrigados a receber e processar estas embalagens e emitir comprovante de devolução para os agricultores (INPEV, 2017). Vale ressaltar que existem cerca 100 centrais de recebimento geral de embalagens vazias no Brasil e uma delas está localizada no município de Pedro Afonso, a 53km de distância da cidade de Guaraí.

O Rio Tranqueira possui, ao longo de suas margens, vegetações nativas como, por exemplo: Ficus adhatodifolia; Pyrostegia venusta; Xylopia aromática; Byrsonima crassifólia; Phyllanthus niruri; Phenakospermum; Croton urucurana; e Mauritia flexuosa (planta indicadora de veredas no Cerrado), demonstradas nas figuras 5D, 5E, e 5F. No entanto, é possível aferir que muitas espécies de plantas nativas já foram removidas pelo desmatamento, a exemplo da espécie Bactris setosa, uma palmeira típica da região, outrora muito encontrada na zona ripária deste Rio, mas que já não é vista com facilidade. Houve relatos de que, para facilitar o manejo agropecuário, os produtores preferem cortá-la.

Os resultados observados neste trabalho corroboram com os dados encontrados na literatura. Martins (2007) cita que a principal causa de degradação das matas ciliares é o desmatamento para a expansão de áreas agrícolas e urbanas. Em segundo lugar, Martins (2007) aponta os incêndios e a extração 
de areia nas áreas ribeirinhas. Ferreira et al. (2004), avaliando as margens de um rio em Minas Gerais, constataram que havia apenas $5 \%$ de mata ciliar remanescente. Ferreira et al. (2004) atribuíram a devastação das zonas ripárias deste rio à exploração de lenha e a implantação de pomares.

Krupek et al. (2006), estudando a vegetação na bacia do Rio das Pedras/PR, encontraram altos níveis de devastação, inclusive junto às nascentes e riachos menores. Chaves e Klein (2009) apontam que no Rio Grande do Sul, é constante a observação de áreas de lavoura chegando até as margens de córregos e lagos e a ausência de área de preservação, muitas vezes apresentando características de degradação avançada por processos erosivos. Já Roberto et al. (2017), em seus estudos sobre a contaminação do Córrego Guará Velho, localizado no município de Guaraí, atribuíram a perda da vegetação ripária desse córrego à constante urbanização do município as proximidades do Córrego.

Neste estudo, observou-se também a existência de um captador de água movido a óleo diesel, como exemplifica a figura 5 C, em péssimo estado de conservação, com vazamento para dentro do Rio. Na margem direita do Rio Tranqueira, na mesma área de estudo, foi observado a permanecia de grande parte de mata ciliar, embora os valores também estejam abaixo do que é exigido por lei. Acredita-se que esta área esteja mais preservada em função da textura demasiadamente arenosa do solo (menos desejável para o cultivo agrícola), em contrapartida, na margem esquerda do rio o solo apresenta textura mais argilosa, ideal para o cultivo de espécies agrícolas.

$\mathrm{Na}$ área de acesso público foi encontrado lixo às margens e dentro do rio, conforme trazido pelas figuras $6 \mathrm{G}, 6 \mathrm{H}$ e $6 \mathrm{l}$. Localizada acima da coleta de dados, encontra-se um espaço utilizado comercialmente para lavagem de veículos, o que gera ainda mais resíduos poluentes ao rio. A vegetação arbórea está fragmentada, como se pode ver na figura $6 \mathrm{~J}$, possuindo pouca vegetação rasteira, sendo insuficiente para filtrar os sedimentos trazidos pela as águas das chuvas.

Nesta área, também foi possível observar maior quantidade de vegetação do lado esquerdo da margem do Rio, no entanto, o valor obtido para o tamanho da mata ciliar ainda se encontra fora da regulamentação exigida pela legislação vigente. Infere-se que a maior quantidade de mata encontrada seja em função da localização ser de uma área pública, o que impossibilita o uso da terra. Em contrapartida, na margem direita do rio, que é de acesso privado, a vegetação também se encontra demasiadamente degradada.

A sobrevivência de diversas espécies animais está diretamente relacionada com a existência da mata ciliar. Segundo Indrusiak et al. (2003, citados por Santos et al., 2008), algumas espécies como Lontra longicaudis, Monodelphis dimidiata e Nyctinomops laticaudatus estão ameaçados de extinção em função da destruição destas áreas. No entanto, segundo Krupek et al. (2006), a mata ciliar não somente é importante para a comunidade de ambiente terrestre, mas também para a biodiversidade dos corpos hídricos. Segundo Krupek et al. (2006), a destruição da mata ciliar altera o índice de luminosidade incidente, a composição química e a temperatura da água, interferindo diretamente sobre as diferentes espécies que ali residem. 
Os resultados obtidos neste trabalho, bem como aqueles relatados em literatura, sejam por observação empírica ou científica, demonstram a importância da adoção de medidas urgentes que visem à contenção dos processos de degradação, a recuperação das áreas degradadas e, principalmente, a preservação das áreas que ainda não foram degradadas, com o objetivo de preservar as fontes naturais de água e a biodiversidade que elas promovem. Estas medidas devem ser de caráter legal, atribuindo responsabilidades pela evolução do processo de desgaste e exigindo medidas efetivas e eficazes na promoção da recuperação das áreas.

As matas ciliares são protegidas pelos principais atos jurídicos, conforme a Lei № 12.651/2012, a qual está conceituada como "área protegida, coberta por vegetação nativa ou não, com a função ambiental de preservar os recursos hídricos, a paisagem, a estabilidade geológica e a biodiversidade, facilitar o fluxo gênico de fauna e flora, proteger o solo e assegurar o bem estar das populações humanas" (BRASIL, 2012). Estes conceitos são aplicáveis ao tipo de vegetação formada ao longo dos corpos hídricos, denominados mata ciliares ou zona ripária, e que são apontados na referida lei como área de preservação permanente (APP). A principal diferença entre a lei revogada e a atual diz respeito à proteção dos Rios, independentemente de sua largura.

O Rio Tranqueira mede aproximadamente $16 \mathrm{~m}$ de largura de uma extremidade à outra. De acordo com o que está previsto na Lei Federal no 12.651/2012, sua vegetação deve possuir 50m de extensão ao longo de suas margens (BRASIL, 2012). No entanto, as quantidades de mata ciliar encontrada no presente estudo, em ambas as áreas de avaliação, estão fora do padrão determinado pela legislação.

Como já relatado anteriormente, às margens do rio foram encontrados plantios agrícola, sendo boa parte da mata ciliar retirada para esta finalidade. A prática da agricultura gera grande valor econômico familiar e a Lei no 12.651/2012, através da 'reserva legal' permite que haja plantio de culturas de ciclo rápido, desde que não haja desmatamento da área de preservação e o proprietário deve conservar pelo menos $20 \%$ da mata nativa, chamado de reserva legal, exceto para a Floresta Amazônica, onde a área de conservação deve ser de $80 \%$ (BRASIL, 2012).

Mediante aos resultados apresentados, é fácil observar que existem falhas na fiscalização ambiental nesta região. Segundo a Secretaria Municipal do Meio Ambiente do Município de Guaraí/TO, órgão responsável pela fiscalização regional, não há problemas em relação à fiscalização, e que os proprietários das áreas desmatadas já foram notificados e multados. 0 órgão responsável também esclareceu que existe um projeto de reflorestamento, denominado 'Projeto Florata', o qual, segundo seus idealizadores, propõe o reflorestamento do Rio Tranqueira desde a nascente, como uma tentativa de amenizar o impacto ambiental do desmatamento. No entanto, faltam verbas para a realização deste projeto. Os responsáveis também alegam realizar palestras de conscientização ambiental, a fim de diminuir a degradação ambiental gerada pela população e proprietários das fazendas do município.

Nada obstante, ao analisar os questionários aplicados ao final da palestra educativa, observa-se que a maior parte dos alunos não tinha noção da importância do rio para a manutenção da biodiversidade ou 
mesmo na geração de renda para muitas famílias rurais, o que traz benefícios econômicos para a cidade de Guaraí. Neste sentido, a palestra educativa colaborou para que os alunos refletissem sobre este tema, incentivando a conscientização e sensibilização para com a proposta de conservação deste recurso natural.

No questionário aplicado, a primeira pergunta questionava a compreensão dos alunos a respeito do termo 'zona ripária', e 89\% responderam não saber do que se tratava. Na segunda pergunta, 58\% dos alunos disseram não conhecer a importância do Rio para a cidade e $72 \%$ não sabiam que a água do Rio Tranqueira contribui para a irrigação das lavouras nas épocas de estiagem.

Durante a palestra foram mostradas aos alunos as imagens realizadas na coleta de dados, do Rio Tranqueira, como explicitado nas figuras 5 e 6. Também foi apresentada aos alunos a Lei Federal 12.651/2012, mostrando que existe regulamentação a certa da exploração de rios e que existem órgãos responsáveis por fazer a fiscalização e garantir o cumprimento da lei. Foi repassada aos alunos a importância da preservação da natureza e de projetos que visem o reflorestamento de Áreas de Preservação Permanente. Diante do que foi exposto, é possível perceber que existe grande necessidade em conscientizar a população a respeito da importância das zonas ripárias, principalmente em escolas e de realizar estudos para averiguar o que resta de cobertura vegetal as margens dos corpos hídricos do Município de Guaraí.

\section{CONCLUSÕES}

Diante dos resultados expostos, é possível concluir que a mata ciliar do Rio Tranqueira não está em conformidade com o que estabelece o novo Código Florestal através da Lei 12.651/12 e não existe atualmente fiscalização eficiente para a proteção deste leito d'água, assim como a falta de conhecimento e de conscientização por parte dos moradores do município acerca da importância de conservação deste recurso hídrico para a homeostase ecológica do município. Através do questionário pode-se perceber que não está sendo desenvolvido um trabalho de conscientização da comunidade em relação à importância do Rio para o ecossistema local e para a comunidade como um todo.

Desta forma, é possível perceber a necessidade de realização de trabalhos que visem a sensibilização da comunidade, assim como, a fiscalização e a punição dos casos omissos com relação à degradação deste recurso natural, sendo necessário uma intervenção enérgica por parte dos órgãos responsáveis para este fim e um árduo trabalho de educação ambiental com os moradores deste município.

\section{REFERÊNCIAS}

ALVARENGA, A. P.; BOTELHO, S. A.; PEREIRA, I. M.. Avaliação da regeneração natural na recomposição de matas ciliares em nascentes na região sul de Minas Gerais. Cerne, Lavras, 2006.

BISHOP, K.; BUFFAN, I.; ERLANDSSON, M.; FOLSTER, J.; LAUDON, H.; SEIBERT, J.; TEMNERUD, J.. Acqua. In: Cognita: the un known headwaters. Hydrological Processes, v.1, n.5, 2008.
BRASIL. Lei n.12651, de 25 de maio de 2012. Dispõe sobre a proteção da vegetação nativa. Brasília: DOU, 2012.

CASTRO, D.; MELLO, R. S. P.; POESTER, G. C.. Práticas para restauração da mata ciliar. Porto Alegre: Catarse, 2012.

CHAVES, A.; KLEIN, V. A.. Importância da Mata Ciliar (legislação) na proteção dos cursos hídricos: alternativas para sua viabilização em pequenas propriedades rurais. Passo Fundo: 2009. 
FERREIRA, D. C.; DIAS, H. C. T.. Situação atual da mata ciliar do ribeirão São Bartolomeu em Viçosa/MG. Revista Árvore, 2004.

GIL, A. C.. Métodos e técnicas de pesquisa social. 6 ed. São Paulo: Atlas, 2008.

IBGE. Instituto Brasileiro de Geografia e Estatística. Censo demográfico. Rio de Janeiro: IBGE, 2016.

INDRUSIAK, C.; EIZIRIK, E.. Carnívoros. In: FONTANA, C. S.; BENCKE, G. A.; REIS, R. E.. Livro vermelho da fauna ameaçada de extinção no Rio Grande do Sul. Porto Alegre: EDIPUCRS, 2003. p.507-533.

INPEV. Instituto Nacional de Processamento de Embalagens Vazias. Normas para descarte de defensivos agrícolas. São Paulo: INPEV, 2017.

KRUPEK, R. A.; FELSKI, G.. Avaliação da Cobertura Ripária de Rios e Riachos da Bacia hidrográfica do Rio das Pedras, Região Centro-Sul do Estado do Paraná. Revista Ciências Exatas e Naturais, v.8, n.2, 2006.

MALHOTRA, N.. Pesquisa de marketing: uma orientação aplicada. 4 ed. Porto Alegre: Bookman, 2006.

MARTINS, S. V.. Recuperação da mata ciliar. 2 ed. Viçosa: Aprenda Fácil, 2007.
MILARÉ, E.; MACHADO, P. A. L.. Novo Código Florestal. São Paulo: RT, 2012

ROBERTO, M. C.; GUIMARÃES, A. P. M.; RIBEIRO, J. L.; CARVALHO, A. V.; NERES, J. C. I.; CERQUEIRA, F. B.. Avaliação do ph, turbidez e análise microbiológica da água do Córrego Guará Velho em Guaraí, Estado do Tocantins. Revista Desafios, v.4, n.4, p.3-14, 2017.

SILVA, I. A.. Clima urbano: uma avaliação do campo térmico urbano do Campus IV da UFPB/Rio Tinto/PB. Revista Brasileira de Geografia Física, v.6, n.5, p.1384-1399, 2013.

SILVA, I. C.; OLIVEIRA, R. M.; SILVA, T. F.. Evidências da degradação ambiental na mata ciliar do rio Itapororoca, no município de Itapororoca/PB. Revista Geonorte, v.1, n.4, p.663-675, 2012.

SILVA, R. V.. Estimativa de largura de faixa vegetativa para zonas ripárias: Uma Revisão. In: SEMINÁRIO DE HIDROLOGIA FLORESTAL: Zonas Ripárias. Anais. Alfredo Wagner: UFSC, 2003.

TOCANTINS. Secretaria do Planejamento e da Modernização da Gestão Pública. Atlas do Tocantins: Subsídios ao Planejamento da Gestão Territorial. 6 ed. Palmas: SEPLAN, 2012.

VARGAS, M.. O gerenciamento integrado dos recursos hídricos como problema sócio ambiental. Ambiente \& Sociedade, v.2, n.5, 1999. 